\title{
Nobel Laureate Richard R. Ernst: Accepting Responsibility in a World Lacking Long-Term Objectives
}

\author{
Marina de Senarclens ${ }^{\star}$
}

\begin{abstract}
Nobel Laureate Richard R. Ernst gave a keynote lecture on the occasion of the tenth anniversary celebrations of the TECHNOPARK ${ }^{\circledR}$ Zurich. He took advantage of the opportunity not only to congratulate the management on the very successful implementation of a promising concept, but also to express his concerns regarding the current developments in society, economy, and politics.
\end{abstract}

Keywords: R.R. Ernst · TECHNOPARK ${ }^{\circledR}$ Zurich

Nobel Laureate Richard R. Ernst gave a keynote lecture on the occasion of the tenth anniversary celebrations of the TECHNOPARK ${ }^{\circledR}$ Zurich. He took advantage of the opportunity not only to congratulate the management on the very successful implementation of a promising concept, but also to express his concerns regarding the current developments in society, economy, and politics.

\section{Identity Crisis and Cultural Decay}

In front of more than 600 guests, Prof. Ernst stigmatised the weak points and negative trends of our time. Since the opening of the Technopark Zurich in 1993, the industrial site Zürich has gone through ups and downs. The number of unemployed soared to almost $6 \%$ in 1997 , dropped below $2 \%$ in 2002, and has again reached almost $4 \%$ today.

Our present era - according to Ernst may be characterized by six facts: Two of them are regarded, so far, as mostly positive, the unlimited problem-solving potential of technology and the unbroken trust in the free market economy. On the other hand, doubts arise regarding our limited re-

*Correspondence: M. de Senarclens PR Manager TECHNOPARK ${ }^{\circledR}$ Zurich

Senarclens, Leu + Partner AG

Freigutstrasse 8

$\mathrm{CH}-8027$ Zürich

Tel.: +4112017300

Fax: +4112029320

E-Mail: marina@senarclens.com

www.senarclens.com

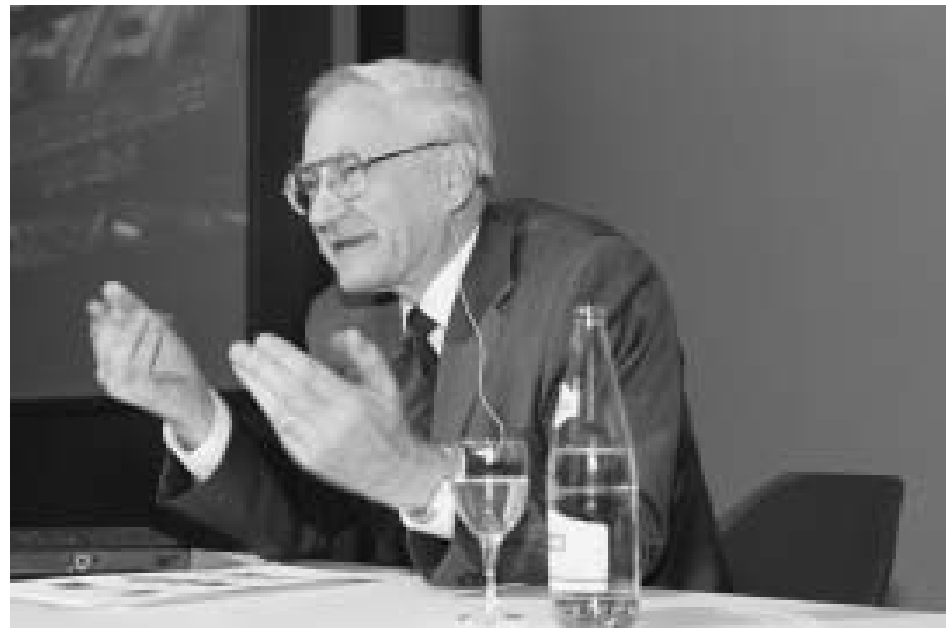

sources, the increasing gap between rich and poor, the nearly complete loss of ethical foundations, and the unlimited dominance by a single super-power. He rates all these observations as potential threats. The trust in the free market economy may negatively influence morals and ethics of our 'free' world: The goal of maximizing profits and share holder value might replace personal responsibility towards society. The Nobel Laureate mentioned some wellknown examples: the Swissair grounding, the ENRON scandal, and the fact that ruthless competition has all too often replaced far-sighted cooperation. The authority of international organizations is also declining. The tattered position of the UN in the Iraq conflict is symptomatic for this deplorable state.

\section{The Hectic Society}

To win we have to speed up. The excessive hectic leads to superficiality, to a sense of insecurity, to a loss of meaning in life, to a decay of culture, and - according to Ernst - to the destruction of our fundamental principles of life. The disease of constant acceleration manifests itself also in the coercion to produce more research results in ever shorter time, disregarding quality, more consumer products, requiring more consumption, and leading to more garbage. "What shall be our true goals?" asked Ernst hauntingly. We are sitting in an acceleration trap and cannot escape! We have to start to ask whether we are running in the right direction. More consumption, promoted by more and more aggressive and astute mar- 
keting, leads to exaggerated greed for money. "Let us satisfy needs instead of creating desires!" One side effect can be seen in the exploding salaries and bonuses of CEOs in comparison to the average salaries in the US, a trend that is also afflicting Europe. In the period 1973-75, a CEO in the US earned 45 times the salary of a worker; 1987-89 the ratio increased to 140 , and 1992-94 already to 220. Today, the salary of a CEO in the US amounts on average to 420 workers' salaries. "Where does this development lead to?" asked Ernst the public, which consisted principally of Swiss CEOs and decision makers. Why not pay part of the bonuses in the form of certificates that have to be spent as charitable contributions? He compared the consumption of luxuries with a contagious disease. "Let's forget consumption, discover ourselves, our senses, and the beautiful world!" The claim for absolute hegemony by the US and their brutal power politics signifies, according to Ernst, a preponderance of selfish acquisitiveness and a missing sense for long-term global welfare.

\section{Responsible Technology Development and Economic Conduct}

To resign and despair in the present situation does not appeal to a Nobel Laureate. Ernst presented some suggestions to the young jubilee Technopark Zurich to counter these alarming developments. The Technopark is asked to initiate an internal discussion group to deal with long-term goals, responsible technology development, and economic conduct. Ethical questions, society responsibility, a catalogue of product requirements, limits of free market economy, and the fostering of international control mechanisms could become subjects for such a discussion group or a Technopark thinktank. Such a working group would share its goals with the entire academic community, the ETH and the Universities. All of them are asked to reflect upon desirable and undesirable future developments on a global scale and to make realistic and visionary suggestions in view of a healthy and sustainable future of all.

Unlimited free speech and the courage to express oneself freely on all conceivable subjects are regarded as essential by the Nobel Laureate. Personal opinions are for him often more important than avoiding errors by all means. A prerequisite for finding new approaches is absolute honesty. Lies poison the climate more than any other deed. A change of paradigm from a "free market economy" to a "responsible market economy" is desirable, and, in consequence, the education of responsible leaders with long-term vision for beneficial tasks in industry and society. At the end of his keynote speech, he cited the French philosopher François Rabelais (14941553): "Science sans conscience n'est que ruine de l'âme" ("Science without conscience ruins the soul") - or in Ernst's free translation: "Technology and economy without conscience lead into the offside".

Received: April 27, 2003 